\title{
THE ROLE OF ONLINE ENTREPRENEURSHIPS IN GENDER EQUALITY
}

\author{
Ahmed A* and Parvez A \\ American International University, Bangladesh
}

\begin{abstract}
In recent years, Bangladesh has seen a meteoric rise of women in Information and Communication Technology (ICT) jobs. This is a direct result of women entrepreneurs conducting businesses through social networking sites. Vast research has already been conducted on investigating participation methods to effectively promote gender equality in ICT-enabled jobs. However, the literature has not closely examined the role the ICT-enabled entrepreneurship plays in closing gender gaps especially in developing countries such as Bangladesh. Additionally, the literature has also not investigated the socio-economic factors influencing women's entrepreneurship. Consequently, this research focuses on identifying and analysing economic, socio-cultural, educational, and psychological factors that motivate women in ICT-enabled entrepreneurship. On conducting an exhaustive literature survey, social networking site-based women-led businesses with less than 5 employees have been selected as a sample for this research. This business size was selected to capture small businesses where entrepreneur women have a direct impact on their businesses. A sample of 100 such businesses has been selected as a sample size. The primary data for this research is collected through a descriptive and specifically designed research survey. The secondary data is collected through a literature review. The datasets were interrogated to analyse the most common responses, factors affecting the most and identify clear distinctive groups drawn. The outcome of this analysis will identify the motivating factors of ICT-based entrepreneurship and how they play a crucial role in closing gender gaps. It is of critical importance because these factors then can be replicated to provide the right infrastructure for other aspiring women entrepreneurs in Bangladesh and other developing countries.
\end{abstract}

Keywords: women empowerment, online entrepreneurship, gender equality, ICT, gender gap

\section{Introduction}

While Bangladesh is predominantly an agricultural country, in the past decades it has emerged as a leader in Information and Communication Technology (ICT) jobs among the developing nations. Bangladesh has one of the highest densities of population in Bangladesh and therefore a huge demand of consumer items. However, for a consumer's point of view, commuting to different places to purchase several items has always remained challenging because of the road traffic often causing a delay.

As a result, when the Internet became widely available in Bangladesh, a meteoric rise of online business was observed. This is because buying online meant the consumer was able to receive different products from vendors of their preferences and was able to get them delivered at home without having to leave the house. Following the prosperous online businesses, social networking platform-based businesses were born. These businesses use social networking platforms as their marketplace and provide benefits of saving commute time, reduction of overheard such as store rentals, offering more competitive prices. 
It has been observed that there has been a meteoric rise of women entrepreneurs in Bangladesh since the Internet became even cheaper. These entrepreneurs are a direct correlation of the availability of the Internet and popularity of the social networking sites. These sites have become a platform that enables ICT-enabled businesses. It is well-known that in developing countries such as Bangladesh businesses directly relate to the country's development. They are also enablers of the country's improved buying capacity.

Consequently, it is important to understand the influencing socio-economic factors behind the women entrepreneurs rise. This paper, therefore, focuses on investigating the factors influencing women's entrepreneurship in social networking platforms and presents results obtained through an original and specially designed survey to capture these factors.

\section{Literature Review}

Several studies consider that the terms "Entrepreneurship" and "Entrepreneur" to be a fairly recent phenomenon because these are so frequently used nowadays. However, these terms are, in fact, centuries old. Although there remains a debate whether Cantillion (1755) or Say (1803) was the first person to coin the term in a publication. Nonetheless, evidence of the term being around as early as during the Middle Ages while the French language was evolving, has been found by Hoselitz (1951) in the historical dictionaries. "Celui qui entreprend quelque chose," meaning" he who gets things done," is probably the most general and the earliest term used for Entrepreneur. In the year 1987, "Entrepreneurship" was mentioned as a crucial factor in creating national wealth, which made it possible to reach the concept and term to the contemporary world. It is worth mentioning that Schumpeter (1934) is regarded as the mastermind of the modern domains of entrepreneurship (Brännback and Carsrud, 2016)

The contemporary meaning world is changing, and the economic dominance is gradually shifting from the West to the East. The economic crisis in 2008, shook the otherwise strong western economies to the core and reminded the world that the stronger the interconnectivity in the global market gets, the more volatile it becomes. There is no doubt that technology plays the most significant role in this change. Modern technology paved the way for small businesses and at the end of the 20th-century, these small businesses showed remarkable growth and success. As a matter of fact, such small businesses become the trailblazer in the development of various "applications" using computers, the internet and mobile technologies which enabled more individuals and small businesses to grow in the global market at a low cost. These individuals and their small business initiatives to cater to different niches of the global market are basically the technology-enabled "Entrepreneurs" and "Entrepreneurship" in the modern world. (Burns, 2016).

There is, however, a gender gap in entrepreneurship. Specifically, in developing countries such as Bangladesh, a number of studies have shown there has been certain barriers on the barriers faced by female entrepreneurs before the availability of the Internet. This has in turn resulted in a gender gap in entrepreneurship and businesses.

World Economic Forum (2006), introduced The Global Gender Gap Index for the first time to build a framework to measure the extent of gender-based disparities and keep tabs on the progress in minimising the gaps over time. The overall gender gap performance is an amalgamation of 
performances across the four dimensions or fundamental categories (subindexes): Economic Participation and Opportunity, Educational Attainment, Health and Survival, and Political Empowerment. So, it is evident, "Economic participation and opportunity" is crucial for minimising the gender gap and ensuring gender equality.

Posadas et al. (2017) stated that gender equality is essential because of its intrinsic and instrumental value. Gender equality matters intrinsically because everyone has basic human rights and the rights should be available to anyone, no matter what one's sex or gender is. Gender equality also matters because it is instrumental in contributing to economic efficiency and the achievement of other desirable development outcomes. Gender equality can contribute to economic development in three ways:

1. It can eliminate barriers that prevent women from accessing education, economic opportunities, and productive inputs that generate economic gains.

2. Gains of the women promote other desired development outcomes, such as increased economic productivity, as well as child nutrition, health, and education, which improve the welfare of future generations.

3. Greater equality of women's participation in community and political organizations leads to more inclusive and representative institutions, which contributes to development.

According to Global Gender Gap Report (2020), Economic Participation and Opportunity subindex is $36.5 \%$ in South Asia, the lowest mark among all regions. However, Bangladesh (overall score of 72.6\%) is the only one of the seven South Asian countries featured in the top 100 of the Global Gender Gap Index 2020 rankings. Whereas, India ranks $112^{\text {th }}(66.8 \%)$ and Pakistan $(56.4 \%)$.

Women in Bangladesh have started to break the barriers of society and joined the working force as entrepreneurs and workers, which was not socially accepted in the recent past. The women have now become aware of the socio-economic rights they have and have ventured to avail the opportunities initiated for them. The majority of women are usually motivated by the economic reason to achieve financial prosperity of their life and family. Women are also motivated by their interests, i.e., as a hobby, particular skill, previous experiences, etc. Another motivating factor next to financial gain is a philanthropic approach among the entrepreneurs that drive them to do something good for people i.e. generating employment (Rahmatullah \& Zaman, 2014). Social media and social networking platforms have been seen as one of the crucial enablers to break those barriers.

"Social Media" refers to the use of web-based and mobile technologies to turn communication into an interactive dialogue. Social media takes on many different forms including internet forums, blogs, microblogging, podcasts, photographs or pictures, video, rating, etc. With the world in the midst of a social media revolution, it is more than obvious that social media like Facebook, Twitter, etc., are used extensively for the purpose of communication. It is convenient to use online social networking for both personal and business use because most of the activities are usually free. A person can scout out potential customers and target markets without spending any extra money (Baruah, 2012)

Online business, Internet business is not new in Bangladesh, the market started to develop rapidly in recent years due to an increase in consumer interest. However, while a large number of medium to large 
size multinational companies were extending their operations in Bangladesh, individual entrepreneurs started to buy and sell using the social group and brand pages in hugely popular social networking site Facebook.com. Initiating a business on Facebook is much more convenient than opening and operating a .com or .com.bd website which requires funding. An existing and growing trend towards Facebook shopping among the young generation in Bangladesh is because the traditional online shops are not providing all the products and services that they desire. (Rahman, 2015).

Sultan and Sharmin (2020) stated that Social media create a vast opportunity for women entrepreneurship in the developing country. Rural educated women are utilizing these opportunities for developing business through virtual platforms. The finding shows that social media compatibility, its usefulness, brand awareness creation is the most significant factors toward the success of women entrepreneurship.

There remains a gap in the current studies to investigate the socio-economic factors on online-based women entrepreneurship and their reasons and factors for success. This research has been taken to evaluate online-based women entrepreneurs who operate their business by using Facebook media. The study also identifies the factors that entrepreneurs admire for their success. This research also evaluates the barrier women entrepreneurs are facing while doing their business. Therefore, the objective of the study was to identify the factors that influence and stand as success factors of women to be an online entrepreneurs through Facebook and to identify the barriers of online-based women entrepreneurship.

\section{Methodology}

The empirical basis for this research is designed from qualitative research carried based on the context described in detail in the Literature Survey section. Upon conducting an exhaustive literature survey as outlined, social networking site-based women-led businesses with less than 5 employees have been selected as a sample for this research. The reason behind selecting businesses with less than 5 employees is based on the fact that this research aims to capture the direct impact entrepreneur women have on their businesses. This research is investigating the socio-economic factors that are driving this entrepreneurship. To capture that in the best possible way is to focus on the businesses where the entrepreneurs are directly involved in every aspect of the business with some or limited help of a few employees. An example scenario is where a woman leads the online store and manages aspects such as procurements, accounts payable, accounts receivable, customer contact, overseeing shipping, etc. However, they enlist help to employees to deliver their goods, consolidate customer feedbacks and enhance marketing, etc. This way they have a direct impact on all aspects have a business and make testbed for studies like this looking to understand socioeconomic factors. Additionally, these employees only make up part of the operation of the online business itself as exemplified. They do not include employees involved on the vendor or customer side involved in manufacturing or purchasing the product as a customer because they do not fall within the scope of this investigation. A sample size of 100 such businesses has been selected for this research. The primary data for this research is collected through a descriptive and specifically designed research survey. The secondary data is collected through a literature review.

The survey was titled as 'Survey on Women Online Small Business Owners' and prepared in Google forms. The aim of this survey was to appropriately portray the research objectives. The research objectives are selected to understand the demographics of the women in Bangladesh conducting online 
social networking-based businesses. Such demographics include their education, their area of usual residence, their motivation behind starting and continuing with online businesses. In particular, the survey questions were divided into several different areas including Demographics, the background of the business and influencing factors. The survey was distributed among women entrepreneurs using academic contacts, chamber of commerce and several online forums.

In analysing the responses received from the survey, this study first looked at the usual place of residence of the entrepreneur. This is crucial to understand the distribution of the entrepreneurs across Bangladesh and understand whether location plays any impact on such entrepreneurship. It is also crucial that any influences of location are identified so that areas of improvement can be considered appropriately. Table 1 represents the distribution of the participants. Over $90 \%$ of the women entrepreneurs participating are from the Metropolitan area as shown below which indicates women living in cities leading the entrepreneurship based on the sample.

Table 1 : Number of entrepreneurs based on their location

\begin{tabular}{|l|l|l|}
\hline Area & Participant & Percentage \\
\hline Metropolitan area & 91 & $91 \%$ \\
\hline Non-Metropolitan area & 9 & $9 \%$ \\
\hline Total & 100 & $100 \%$ \\
\hline
\end{tabular}

Next, the analysis also investigates the level of education among these women and therefore understand the role education plays in taking business risk. This is very important to understand the level of education and its role in entrepreneurship as that feedback is important for both Government and nongovernment organisations to take further steps where necessary. According to the analysis in this research $48 \%$ of women have received graduate education comprising nearly half of the sample size as shown in Fig. 1. Fig. 1 also shows that the other half of the sample size is nearly evenly distributed between non-graduate (24\%) education and post-graduation (28\%) education. It is however clear that most entrepreneurs have at least completed a graduate-level of studies and make up for $76 \%$ of the women entrepreneurs. 


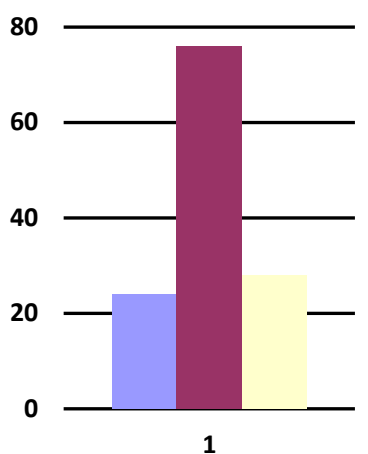

Figure 1: Education level of women entrepreneurs (\%).

Another important key to understanding online entrepreneurship is to understand their length of life span. While selling a few items online is business and can be profitable, that does not provide sustainable income or financial freedom through online entrepreneurship. The number of businesses consistently operating is a strong sign for women's entrepreneurship. Analyzing the length of the entrepreneurship, the following is observed as presented in Table 2. It is observed that only a few businesses have been operating for over 4 years.

Table 2 : Length of Entrepreneurship

\begin{tabular}{|l|l|}
\hline Area & Frequency \\
\hline less than 6 months & 23 \\
\hline 6 months- less than 1 year & 25 \\
\hline 1 year- 2 years & 28 \\
\hline more than 2 years- 4 years & 17 \\
\hline more than 4 years & 7 \\
\hline
\end{tabular}

This study then investigates the profitability of these businesses as it is crucial to understand whether these women entrepreneurs can run their business on profit and achieve financial freedom. When analysing the profitability of these businesses, it has been observed that most of the businesses are making profits as shown in Fig. 2. 


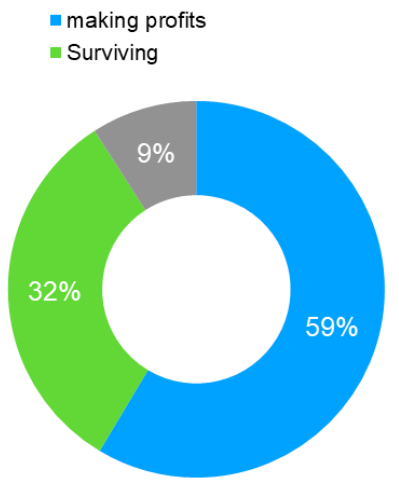

Figure 2: Profitability Analysis

Next, we analysis psychological factors behind women entrepreneurship. It has been observed from the analysis that overwhelmingly $85 \%$ entrepreneurs want to achieve work-life balance which is what motivated them to social networking-based businesses. Being their own boss was found a motivating factor that motivated $84 \%$ of entrepreneurs. However, only $66 \%$ of entrepreneurs indicated that improving social status has been a motivating factor. The following table also presents the percentage of the reasons for starting a business to present a more in-depth analysis of these psychological factors.

Table 3: Reasons for stating an online business

\begin{tabular}{|l|l|}
\hline Reasons & Percentage (\%) \\
\hline to become financially independent & 83 \\
\hline to contribute to your family financially & 83 \\
\hline $\begin{array}{l}\text { to improve social status of your family } \\
\text { to get a better work-life balance }\end{array}$ & 66 \\
\hline to be your own boss & 85 \\
\hline
\end{tabular}

Finally, this paper analysis the outcomes achieved because of the entrepreneurship. These outcomes indicate some of the other phycological factors that influence these entrepreneurs. As seen in Fig. 3, financial freedom and a future business extension remain motivating factors for the majority. 


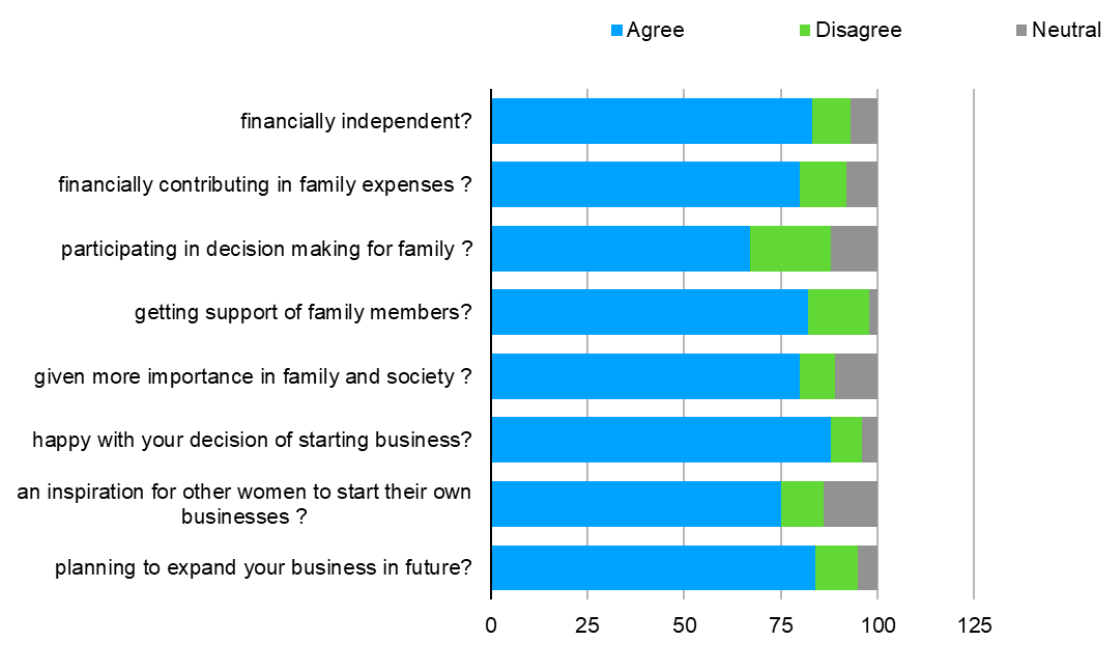

Figure 3: Outcome Analysis

\section{Conclusion}

This study has clearly shown through the analyses taken is that educated women in Bangladesh are exploring the potentials of social networking-based businesses. The availability of the Internet has changed the way women employ themselves in Bangladesh. They are no longer looking for paid employment. They are taking on challenges on entrepreneurship especially by tapping into the potentials of social networking-based platforms. One of the key motivating factors behind such entrepreneurship is seen to be the idea of work-life balance. This has become one of the dominant factors for women to run their own businesses which provides them with better control to balance their lives. Social networking-based entrepreneurship provides these women with that perfect opportunity to pave their way towards businesses often from the comfort of their own home and without the burdens of a traditional brick and mortar store. As a result of this, the gender gap in ICT-related businesses and jobs are closing. This will in turn create a more diverse workplace and provide further financial stability to women.

It is therefore understood from the analysis that highly educated women of metropolitan areas are leading entrepreneurship. This is possibly a direct result of the opportunities available in the cities still more than the non-metropolitan areas. Social networking-based businesses are still in their infancy and achieving work-life balance is one of the key factors that motivate entrepreneurship dominantly.

This study clearly indicated the online businesses are run by women residing in metropolitan areas of Bangladesh. This is directly correlated to both availability and accessibility to the Internet. While most rural and regional areas of Bangladesh are within at least 3G Internet network, they are often not available and accessible to women. This is because they are not aware of the potentials of the Internet. To combat this challenge and further enhance gender empowerment through online businesses, it is crucial to train these women ICT skills and entrepreneurship through school curriculums and external community training. Such training will provide skills and confidence to women in rural and regional areas of Bangladesh to take up opportunities of online businesses and empower themselves. 
While this research investigated social networking-based entrepreneurship, the investigation has not expanded to analyse the type of businesses led by women. In the future this research will be expanded to further investigate the type of business led by women entrepreneurs.

\section{References}

Brännback, M., \& Carsrud, A. L. (2016). Why Entrepreneurship Became Important. In Fundamentals for becoming a successful entrepreneur: From business idea to launch and management, 6-7. Pearson Education, Inc. http://ptgmedia.pearsoncmg.com/images/9780133966817/samplepages/9780133966817.pdf

Rahmatullah, M., \& Zaman, F. (2014). Female Entrepreneurship in Bangladesh: Constraints, Motivation and Success. Bangladesh e-Journal of Sociology, 11(2), 65-77.

Burns, P. (2016). Entrepreneurship and small business: Start-up, growth and maturity (4th ed.). Palgrave Macmillan.

Schwab, K., Crotti, R., Geiger, T., Ratcheva, V., \& World Economic Forum. (2019). Global gender gap report 2020 insight report. World Economic Forum. http:// reports.weforum.org/global-gendergap-report-2020/dataexplorer

Posadas, J., Paci, P., Sajaia, Z., \& Lokshin, M. (2017). Measuring Gender Equality. World Bank Publications, 5-9. https://doi.org/10.1596/978-1-4648-0775-6

Baruah, T. D. (2012). Effectiveness of Social Media as a tool of communication and its potential for technology enabled connections: A micro-level study. International Journal of Scientific and Research Publications, 2(5), 1-10.

Rahman, S. M. (2015). Consumer Expectation from Online Retailers in Developing E-commerce Market: An Investigation of Generation Y in Bangladesh. International Business Research, 8(7), 121137. https://doi.org/10.5539/ibr.v8n7p121

Sultan, M. T., \& Sharmin, F. (2020). An Exploratory Investigation of Facebook Live Marketing by Women Entrepreneurs in Bangladesh. In G. Meiselwitz, Social Computing and Social Media. Participation, User Experience, Consumer Experience, and Applications of Social Computing, 415430. Springer International Publishing. https://doi.org/10.1007/978-3-030-49576-3_30 